\title{
CORRELATION OF FINE NEEDLE ASPIRATION CYTOLOGY WITH HISTOPATHOLOGY IN DIAGNOSIS OF THYROID LESIONS
}

Sunita. K.Shere ${ }^{1}$, Anjali S. Kulkarni², Pragati P Phulgirkar ${ }^{3}$, Shazia Anjum4, Sunita P. Patil5, Rajan Bindu6.

1. Assistant Professor, Department of Pathology, Government Medical College Aurangabad.

2. Assistant Professor, Department of Pathology, Government Medical College Aurangabad.

3. Assistant Professor, Department of Pathology, Government Medical College Aurangabad.

4. Assistant Professor, Department of Pathology, Government Medical College Aurangabad.

5. Assistant Professor, Department of Pathology, Government Medical College Aurangabad.

6. Professor \& HOD, Department of Pathology, Government Medical College Aurangabad.

\section{CORRESPONDING AUTHOR}

Dr. Sunita. K. Shere,

Vasundhara Colony,

Plot No 18, Nandanwan Colony,

Aurangabad.

Email- aharbade@yahoo.com

\section{HOW TO CITE THIS ARTICLE:}

Sunita. K. Shere, Anjali S. Kulkarni, Pragati P Phulgirkar, Shazia Anjum,Sunita P. Patil, Rajan Bindu. "Correlation of Fine Needle Aspiration Cytology with Histopathology in Diagnosis of Thyroid Lesions". Journal of Evolution of Medical and Dental Sciences 2013; Vol2, Issue 26, July 1; Page: 4826-4831.

ABSTRACT: - BACKGROUND: FNAC is emerging as the first line of diagnostic test performed at the patient's first visit, for all types of thyroid enlargement. FNAC thyroid gland is safe, inexpensive, minimally invasive and highly accurate in the diagnosis of nodular diseases. MATERIALS AND MEHTODS: This prospective study was carried out at department of pathology GMCH Aurangabad.80 cases of thyroid masses were thoroughly examined clinically after taking detail history After FNAC; all the patients were subjected to surgery after preoperative preparation and anesthesia checkup. Thyroidectomy specimen was evaluated by histopathological examination. Results- In the present study both FNAC and histopathology was done in 80 patients of thyroid lesions. Out of 80 cases, 74 cases were benign and 6 cases were malignant on histopathology. On cytology 72 cases were benign, 6 cases were malignant, one case was hemorrhagic, and one case was suspicious smear which was the only one false positive case. The cyto histopathological correlation in tumor like lesions, benign tumor and for malignancy is $96.87 \%, 100 \%$ and $100 \%$ respectively. Sensitivity was $100 \%$ and specificity was $98.57 \%$. Conclusion-FNAC diagnosis of malignancy is highly significant and such patients should be subjected to surgery. A benign FNAC diagnosis should be viewed with caution as false negative results do occur and these patients should be followed up and any clinical suspicion of malignancy even in the presence of benign FNAC requires surgery.

KEY WORDS: FNAC, Histopathology, correlation, thyroid lesions

INTRODUCTION: FNAC is emerging as the first line of diagnostic test performed at the patient's first visit, for all types of thyroid enlargement. FNAC thyroid gland is safe, inexpensive, minimally invasive and highly accurate in the diagnosis of nodular diseases. 


\section{ORIGINAL ARTICLE}

Nodular enlargement of thyroid gland is frequent and constitutes the commonest indication for thyroidectomy. Thyroid nodule may be cystic or solid .Most of the cystic nodules are benign in nature except few cases of papillary carcinoma. Among the solid nodule only about $3 \%$ are malignant tumours. However thyroid carcinoma closely resembles its benign counterpart in physical characteristics, measurable physiological parameters such as serum T3/T4 levels and ultrasonic characteristics. Therefore the surgical excision of the nodule and its histopathological examination is the only way to differentiate between the more benign and much less frequent malignant nodules. Since most of the nodules are benign, symptomless and small in size, they do not require surgical excision. The purpose of our study is to evaluate the use of simple and easy technique like fine needle aspiration to differentiate between benign and malignant thyroid nodules. Although surgical diagnosis is the commonest method of tissue diagnosis, cytological diagnosis by FNAC has been in practice since 1930. [11]

FNAC has becoming a common diagnostic procedure replacing other diagnostic methods as it requires no anaesthesia, it is easy to perform and can be repeated without much discomfort to the patient and has a high diagnostic accuracy.

MATERIALS AND MEHTODS: This prospective study was carried out at department of pathology GMCH Aurangabad.80 cases of thyroid masses were thoroughly examined clinically after taking detail history. Necessary clinical investigations were done and patients were subjected to FNAC using 22 to 23 gauge needle. Smears were prepared, and fixed by using 95\% ethyl alcohol. And then stained by papanicolua's method and the cytological diagnosis was made. After FNAC, all the patients were subjected to surgery after preoperative preparation and anaesthesia checkup. Thyroidectomy specimen was evaluated by histopathological examination. Specimens were processed in automated tissue processing units and staining was performed with routine haematoxylin and eosin stain.

The Pearson chi square test is used to compare the possible correlation between FNAC and Histopathology of thyroid lesions.

The present study was conducted after obtaining the ethical approval from the Ethical Review Committee.

OBSERVATIONS: FNAC was done in 80 patients out of which 79 cases aspirates were adequate to opine and one was hemorrhagic in nature, no cytological opinion possible

In present study 73 cases $(91.25 \%)$ were females and 7 cases (8.75 \%) were males. So the ratio was 1.14: o.1. Maximum number of cases observed in the age group of 31-40 years. No case was observed in age group of 0-10 and above 71 years

Commonest complaint was neck swelling followed by dysphasia

TABLE 1: Showing Category Wise Distribution of Cases on Cytological and Histopathological Basis

\begin{tabular}{|l|l|l|l|}
\hline Sl. No. & Thyroid lesions & Cytological diagnosis & Histopathological diagnosis \\
\hline 1 & Tumor like lesions & $62(77.5 \%)$ & $64(80 \%)$ \\
\hline 2 & Benign lesions & $10(12.5 \%)$ & $10(12.5 \%)$ \\
\hline 3 & Malignant lesions/neoplasms & $6(7.5 \%)$ & $6(7.5 \%)$ \\
\hline 4 & Suspicious & $1(1.25 \%)$ & 0 \\
\hline 5 & Hemorrhagic & $1(1.25 \%)$ & 0 \\
\hline & Total & $80(100 \%)$ & $80(100 \%)$ \\
\hline
\end{tabular}


Out of 80 cases on FNAC 62(77.5\%) were Tumor like lesions, 10(12.5\%) Benign lesions, $6(7.5 \%)$ Malignant lesions/neoplasm, one case was suspicious and one case was hemorrhagic.

On Histopathology, 64(80\%) were Tumor like lesions, 10(12.5\%) were Benign lesions and 6 (7.5\%) were Malignant lesions.

All the cases diagnosed on cytology as tumor like lesions were confirmed on histopathological examination. Out of 62 cases (77.5\%) only two cases on histopathology diagnosed as tumor like lesion were different on cytology $(80 \%)$.

TABLE 2: Showing Various Lesions of Thyroid, Observed On Cytology And Histopathological Examination (80 Cases) *

\begin{tabular}{|l|l|l|l|}
\hline Sl. No. & Lesion type & Cytological diagnosis & Histopathological diagnosis \\
\hline I & Tumor like lesions & & \\
\hline 1 & Colloid goiter & $36(45 \%)$ & $40(50 \%)$ \\
\hline 2 & Colloid goiter with cystic change & $14(17.50 \%)$ & $10(12.50 \%)$ \\
\hline 3 & Thyroglossal duct cyst & $2(2.5 \%)$ & $2(2.5 \%)$ \\
\hline 4 & Acute thyroiditis & $1(1.25 \%)$ & $1(1.25 \%)$ \\
\hline 5 & Granulomatous thyroiditis & $3(3.75 \%)$ & $4(5 \%)$ \\
\hline 6 & Lymphocytic thyroiditis & $6(7.5 \%)$ & $7(8.75 \%)$ \\
\hline II & Benign tumors & & \\
\hline 1 & Follicular adenoma & $9(11.25 \%)$ & $9(11.25 \%)$ \\
\hline 2 & Hurthle cell adenoma & $1(1.25 \%)$ & $1(1.25 \%)$ \\
\hline III & Malignant tumors & & \\
\hline 1 & Follicular carcinoma/neoplasm & $2(2.5 \%)$ & $2(2.5 \%)$ \\
\hline 2 & Papillary carcinoma & $3(3.75 \%)$ & $3(3.75 \%)$ \\
\hline 3 & Anaplastic carcinoma & $1(1.25 \%)$ & $1(1.25 \%)$ \\
\hline IV & Suspicious & $1(1.25 \%)$ & 0 \\
\hline V & Hemorrhagic & $1(1.25 \%)$ & 0 \\
\hline & Total & $80(100 \%)$ & $80(100 \%)$ \\
\hline
\end{tabular}

Maximum number of cases were colloid goitre36(45\%) cases followed by colloid goiter with cystic change in 14(17.50\%) cases .Benign tumors in 10,malignant lesions were observed in 6 cases. one aspirate was suspicious which turned out to be benign lesion.

TABLE 3 Showing Cyto histopathological Correlation of 62 Tumor Like Lesions on Cytology and 64 Cases on Histopathology

\begin{tabular}{|l|l|l|l|l|}
\hline Sl. no. & Diagnosis & Cytological & histopathological & percentage \\
\hline 1 & Colloid goiter & 36 & 40 & $90 \%$ \\
\hline 2 & Colloid goitre with cystic change & 14 & 10 & $71.42 \%$ \\
\hline 3 & Thyroglossal cyst & 02 & 02 & $100 \%$ \\
\hline 4 & Acute thyroiditis & 01 & 01 & $100 \%$ \\
\hline 5 & Granulomatous thyroiditis & 03 & 04 & $75 \%$ \\
\hline 6 & Lymphocytic thyroiditis & 06 & 07 & $85.71 \%$ \\
\hline & Total & 62 & 64 & $96.87 \%$ \\
\hline
\end{tabular}


The accuracy of correlation amongst the tumor like lesions was $96.87 \%$ Two case of colloid goitre diagnosed on cytology were turned out to be thyroiditis on histopathology, one turned out to colloid goitre with lymphocytic thyroiditis and one colloid goitre with non-specific lymphocytic thyroiditis. In one case, aspirate was hemorrhagic, on histopathology diagnosed as colloid goitre.

TABLE 4 Showing Cyto histopathological Correlation in Benign Tumors

\begin{tabular}{|l|l|l|l|}
\hline Diagnosis & Cytological diagnosis & $\begin{array}{l}\text { Histopathological } \\
\text { diagnosis }\end{array}$ & $\%$ correlation \\
\hline Follicular adenoma & $09(90 \%)$ & $09(90 \%)$ & $100 \%$ \\
\hline Hurthle cell adenoma & $01(10 \%)$ & $01(10 \%)$ & $100 \%$ \\
\hline Total & $10(100 \%)$ & $10(100 \%)$ & $100 \%$ \\
\hline
\end{tabular}

Above table shows $100 \%$ cyto histopathological correlation in benign tumors

TABLE 5: Showing Cyto histopathological Correlation between Malignant Lesions of Thyroid

\begin{tabular}{|l|l|l|l|}
\hline Diagnosis & Cytological diagnosis & $\begin{array}{l}\text { Histopathological } \\
\text { diagnosis }\end{array}$ & Percent correlation \\
\hline $\begin{array}{l}\text { Follicular } \\
\text { neoplasm/follicular } \\
\text { carcinoma }\end{array}$ & $2(33.33 \%)$ & $2(33.33 \%)$ & $100 \%$ \\
\hline Papillary carcinoma & $3(50 \%)$ & $3(50 \%)$ & $100 \%$ \\
\hline Anaplastic carcinoma & $1(16.66 \%)$ & $1(16.66 \%)$ & $100 \%$ \\
\hline Total & $6(100 \%)$ & $6(100 \%)$ & $100 \%$ \\
\hline
\end{tabular}

Above table shows $100 \%$ cyto histopathological correlation in malignant lesions of thyroid

TABLE 6: Showing Overall Cyto histopathological Correlation in Present Study

\begin{tabular}{|l|l|l|}
\hline Sl. No. & Lesions & Percent correlation \\
\hline 1 & Tumor like lesions & $96.87 \%$ \\
\hline 2 & Benign lesions & $100 \%$ \\
\hline 3 & Malignant lesions & $100 \%$ \\
\hline
\end{tabular}

Above table shows there is $100 \%$ cyto histopathological correlation in benign and malignant tumors of thyroid and $96.87 \%$ correlation in tumor like lesions of thyroid gland.

\section{SENSITIVITY AND SPECIFICITY OF THE STUDY}

TP-True positive, FP-False positive, TN-True negative, FN-False negative

TP-1, FP-1TN-1 TN-71, FN-0

Sensitivity $=\mathrm{TP} /(\mathrm{TP}+\mathrm{FN}) \mathrm{X} 100,=1 /(1+0) \mathrm{X} 100=100 \%$

Specificity $=\mathrm{TN} /(\mathrm{TN}+\mathrm{FP}) \mathrm{X} 100,=71 /(71+1) \mathrm{X} 100=98.61 \%$

Positive predictive value $=\mathrm{TP} /(\mathrm{TP}+\mathrm{FP}) \mathrm{X} 100,=1 /(1+1) \mathrm{X} 100=50 \%$

Negative predictive value $=\mathrm{TN} /(\mathrm{TN}+\mathrm{FN}) \mathrm{X} 100,=71 /(71+0) \mathrm{X} 100=100 \%$

The present study showed $98.61 \%$ sensitivity and $100 \%$ specificity

Accuracy rate $=\mathrm{TP}+\mathrm{TN} /(\mathrm{TP}+\mathrm{TN}+\mathrm{FP}+\mathrm{FN}) \mathrm{X} 100,=1+71 /(1+71+1) \mathrm{X} 100=98.63 \%$

Accuracy rate in the present study is $98.63 \%$ 


\section{ORIGINAL ARTICLE}

DISCUSSION: A significant correlation between aspiration cytology and paraffin sections have been recorded in many series.

We reported the smears not as positive or negative for malignancy but also tried to subclassify benign thyroid lesions and malignant lesions and correlated it with histopathology In the present study age of the patient varied from 10-71 years. These findings are in accordance with Fenn et al (1961) ${ }^{[5]}$ and Rao et al (1971)[12]

In present study female to male ratio was 1.14:0.1 which is comparable with ratio reported by Kapur et al 1982.[12]

TABLE N0.7: showing comparison of cyto histopathological correlation of tumor like lesions, benign lesions and malignant lesions with various studies

\begin{tabular}{|c|c|c|c|c|c|c|c|}
\hline \multirow[t]{2}{*}{ Author } & \multirow{2}{*}{$\begin{array}{l}\text { Tumor } \\
\text { like } \\
\text { Lesion } \\
\text { Cytology }\end{array}$} & \multirow[b]{2}{*}{$\begin{array}{l}\text { Histopath } \\
\text { ology }\end{array}$} & \multicolumn{2}{|c|}{$\begin{array}{l}\text { Benign---- } \\
\text { Lesions }\end{array}$} & \multirow{2}{*}{$\begin{array}{l}\text { Malignant } \\
\text { Lesions } \\
\text { Cytology }\end{array}$} & \multirow{2}{*}{\begin{tabular}{|l|} 
\\
$\begin{array}{l}\text { Histopath } \\
\text { ology }\end{array}$ \\
\end{tabular}} & \multirow[t]{2}{*}{ Inadequate } \\
\hline & & & Cytology & $\begin{array}{l}\text { Histopath } \\
\text { ology }\end{array}$ & & & \\
\hline $\begin{array}{l}\text { Jan } \\
\text { Silverman } \\
(1986)\end{array}$ & $60.84 \%$ & $28.33 \%$ & $23.62 \%$ & $58.33 \%$ & $1.61 \%$ & $13.33 \%$ & \\
\hline Hall(1989) & $64.02 \%$ & $29.17 \%$ & $9.43 \%$ & $19.44 \%$ & $9.30 \%$ & $51.38 \%$ & \\
\hline $\begin{array}{l}\text { Joel F } \\
\text { Hamburger } \\
(1989)\end{array}$ & $61.56 \%$ & $60.46 \%$ & $6.52 \%$ & $5.42 \%$ & $5.5 \%$ & $34.10 \%$ & \\
\hline $\begin{array}{l}\text { Present } \\
\text { study(2009) }\end{array}$ & $77.5 \%$ & $80 \%$ & $12.5 \%$ & $12.5 \%$ & $7.5 \%$ & $7.5 \%$ & \\
\hline
\end{tabular}

Above table shows that the correlation between cytological and histopathological diagnosis in the thyroid lesions are well in accordance with the studies documented.

Sensitivity observed in the present study was $100 \%$ which was comparable with Silverman (1986).[13] While specificity observed in the present study was $91.6 \%$ which was well in accordance with Silverman et al and Rosen et al (1993). Accuracy rate in the present study was $98.63 \%$ which is similar to reports published by Young et al [14] (1981), Charry et al (1983)[4]and Anderson(1987).[2] which was respectively $94.8 \%, 100 \%, 98.4 \%$.

Hence the cytological screening of the patients is must for quick diagnosis and selection of cases for surgical management, so that patient can receive treatment earlier.

SUMMARY AND CONCLUSION: In the present study both FNAC and histopathology were done in 80 patients of thyroid lesions. Out of 80 cases ,74 cases were benign and 6 cases were malignant on histopathology. On cytology 72 cases were benign, 6 cases were malignant, one case was hemorrhagic, and one case was suspicious smear which was the only one false positive case.

The cyto histopathological correlation in tumor like lesions was $96.87 \%$. As 4 cases were diagnosed as colloid goitre with cystic change on histopathology, which turned out to be colloid goitre on histopathology. Cyto histopathological correlation in benign lesions was 100\%. Four (4) 


\section{ORIGINAL ARTICLE}

malignancies diagnosed on cytology were correlated on histopathology and two cases diagnosed as follicular neoplasm on cytology were turned out to be malignant on histopathology, so correlation was $100 \%$. Sensitivity was $100 \%$ and specificity was $98.57 \%$.

We concluded that FNAC diagnosis of malignancy is highly significant and such patients should be subjected to surgery. A benign FNAC diagnosis should be viewed with caution as false negative results do occur and these patients should be followed up and any clinical suspicion of malignancy even in the presence of benign FNAC requires surgery.

GMCH: Aurangabad, All my co-authors

\section{REFERENCES}

1. Ackerman M.et al: Sensitivity and specificity of fine needle aspiration cytology in the diagnosis of tumors of the thyroid gland. Acta cytol. 1985; 29: 850-55.

2. Anderson J .B and Webb A.J: Fine needle aspiration biopsy and the diagnosis of thyroid cancer. Brit J of Surg. 1987; 74:292-96.

3. Bancroft J .D. and Gamble M: Theory and practice of histological technique, 5thEdi.by Churchill Livingstone, 2002.

4. Charry A.K.et al: Role of fine needle aspiration biopsy in thyroid swellings. Ind J of Surg.1983; 113:346-49.

5. Feen A.S et al: Study of thyroid adenomas. Ind J of Surg.1961; 193-96.

6. Hall T.L.et al: Sources of diagnostic error in fine needle aspiration of the thyroid. Cancer.1989; 63:718-25.

7. Hamburger J.F.et al: Increasing the accuracy of fine needle biopsy for thyroid nodules. Arch Pathol Lab Med. 1989; 63:1035-41.

8. Kapur M. M. et al: Solitary thyroid nodule. Ind J of Surg. 1982; 174-78.

9. Koss L.G and Zajicek J: Diagnostic cytology and its histopathological bases, 4 th Edi. by J.B. Lippincott Co. Philadelphia. 1992; Vol.2.

10. Orell $\mathrm{S}$ et sal: The thyroid gland, Manual and Atlas of fine needle aspiration cytology. By Churchil Livingstone, New York, Philadelphia, 3rd Edi. 1999; 109-44.

11. Pandit A.A. and Kinare S.G: Fine needle aspiration cytology of thyroid. Ind J of Cancer.1986; 23: 54-58.

12. Rao S and Rao K: Solitary nodules in thyroid. Ind J of Surg. 1971; 44-51.

13. Silverman.J.F.et al: The role of fine needle aspiration biopsy in thyroid swelling. Ind J of Surg. 1983; 346-49.

14. Young J.E.M.et al: Needle aspiration cytologic biopsy in head and neck masses. The Amer J of Surg. 1981; 484-89. 